\title{
Late massive haemoptyses from bronchopulmonary collaterals in infarcted segments following pulmonary embolism
}

\author{
C.S. Thomas*, J. Endrys*, A. Abul**, G. Cherian**
}

\begin{abstract}
Late massive haemoptyses from bronchopulmonary collaterals in infarcted segments following pulmonary embolism. C.S. Thomas, J. Endrys, A. Abul, G. Cherian. (C) ERS Journals Ltd 1999.

ABSTRACT: Massive, recurrent haemoptyses requiring blood transfusions occurred in a patient who had been diagnosed as having pulmonary thromboembolism 3 months earlier. To the authors' knowledge this is the first case report of this kind, in which massive haemoptyses were proved to be caused by large bronchopulmonary collaterals that had developed in the infarcted lung segments affected by embolism. Selective embolization of the collaterals proved to be therapeutic and life saving. Eur Respir J 1999; 13: 463-464.
\end{abstract}

\author{
*Depts of Cardiology and Chest Diseases, \\ Chest Hospital and **Faculty of Medi- \\ cine, Kuwait. \\ Correspondence: G. Cherian, Faculty of \\ Medicine, P.O. Box 24923, Safat 13110, \\ Kuwait, Fax: 009565338907 \\ Keywords: Bronchial artery embolization \\ bronchopulmonary collaterals \\ massive haemoptyses \\ pulmonary embolism
}

Received: May 181998

Accepted after revision October 21998
Studies in animals have demonstrated the development of bronchopulmonary collaterals in segments of lung affected by experimental pulmonary artery ligation or embolism $[1,2]$. They have also been reported in patients with pulmonary embolism [3-5]. Such collaterals start to evolve in the first week after embolization and are fully developed after about 1 month. This study reports on a patient with pulmonary embolism in whom such bronchopulmonary collaterals led to late, massive, recurrent haemoptyses.

\section{Case report}

A 40-yr-old Arab male first presented with episodes of cough, chest pain and mild haemoptyses. A diagnosis of pulmonary thromboembolism was established and he was started on warfarin. The drug was discontinued 2 months later with the recurrence of haemoptyses and the bleeding was attributed to warfarin. He presented 1 month later with massive haemoptyses over the preceding 2 days, while off warfarin. He required 4 units of blood over $24 \mathrm{~h}$.

Investigations were conducted over the 3 -month period. The haemoglobin level, which was $12.5 \mathrm{~g} \cdot \mathrm{L}^{-1}$, dropped to $8 \mathrm{~g} \cdot \mathrm{L}^{-1}$ during the episodes of haemoptyses. The prothrombin time on admission with massive haemoptyses was 1.14 (international normalized ratio).

The chest radiograph at the initial episode of chest pain and haemoptyses showed plate atelectasis in the right lower zone. A lung scan showed ventilation-perfusion mismatch consistent with pulmonary embolism.

An ascending venogram revealed a thrombus in the left common iliac vein. A diagnosis of pulmonary thromboembolism was made on the basis of the clinical picture and the above investigations and the patient was started on anticoagulants. Neither transoesophageal echocardiography nor a spiral computed tomography scan was performed. During the recurrence of haemoptyses, bronchoscopy showed that the left side was normal, and fresh blood clots were seen in the right middle and lower lobe bronchial orifices, confirming the site of bleeding. Bleeding from bronchopulmonary collaterals was suspected.

At cardiac catheterization the pulmonary artery pressure was $40 / 11$ and the mean pressure $24 \mathrm{mmHg}$. The mean pulmonary capillary wedge pressure was $8 \mathrm{mmHg}$. Pulmonary arteriography revealed an abrupt cut-off of the branches to the right lower lobe (fig. 1), confirming the earlier diagnosis of pulmonary embolism. Bronchial arteriography demonstrated a dilated bronchial artery feeding a large mesh of bronchopulmonary collaterals to the basal segments of the right lower lobe (fig. 2a), corresponding to the area affected by embolism.

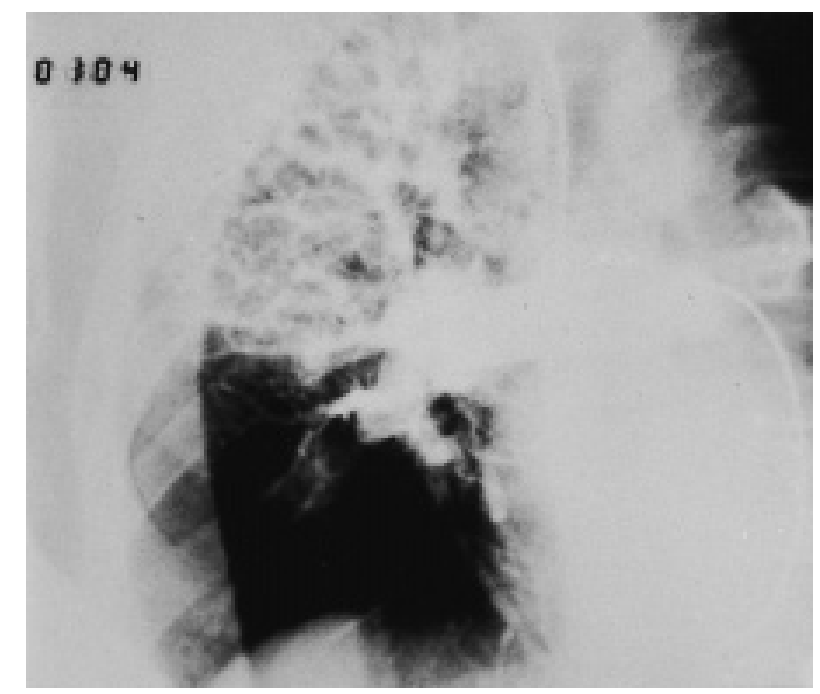

Fig. 1. - Right pulmonary arteriogram showing abrupt cutoff and obstruction of flow to the right lower lobe. 

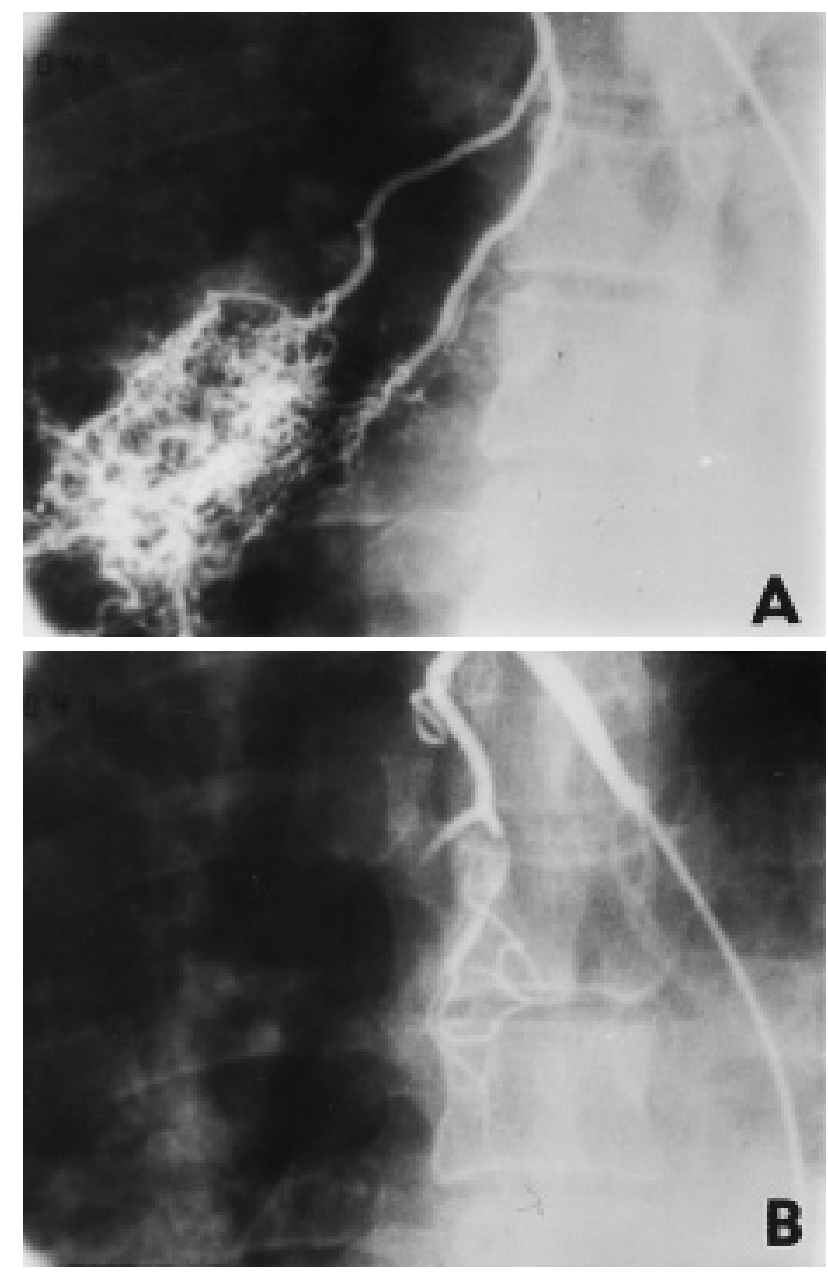

Fig. 2. - Selective bronchial arteriography before (A) and after (B), selective embolization with polyvinyl acetate. The mesh of bronchopulmonary collaterals has disappeared in (B).

The bronchial artery feeding the collaterals was selectively embolized with polyvinyl acetate in alcohol solution (Vilan) [6]. After embolization there was complete obliteration of the collaterals (fig. 2b).

The response to the procedure was dramatic. Haemoptyses ceased and there was no recurrence over the next 15 months.

\section{Discussion}

This report has described a patient with chronic pulmonary thromboembolism confirmed by pulmonary angiography. Although he had a clear single episode 3 months before presentation, in view of the thrombus in the left common iliac vein, he could have had multiple subclinical small pulmonary emboli resulting in pulmonary hypertension. Large bronchopulmonary collaterals had developed in the large segment of the lung affected by the embolus (fig. 2a) and led to massive, life-threatening haemoptyses. Therapeutic embolization in such a situation, which the authors believe is being reported for the first time, proved to be life saving.

Bronchopulmonary collateral flow has been found to be increased significantly after occlusion of the pulmonary artery branches by ligation or embolization $[1,2]$. Matsuda [4] performed bronchial arteriography in patients with documented pulmonary embolism and found that all of the patients in the chronic stage had bronchial to pulmonary arterial collaterals with antegrade filling of the distal pulmonary arteries.

ENDRYs et al. [5] recently demonstrated vastly increased bronchopulmonary blood flow in all patients with chronic pulmonary embolism both with and without pulmonary hypertension. In the present patient prompt and complete cessation of massive haemoptyses during and after the embolization procedure proved that bronchopulmonary collaterals were the source of the bleeding.

In summary, a patient with documented pulmonary embolism developed late massive haemoptyses requiring multiple blood transfusions. The bleeding was from bronchopulmonary collaterals that had developed in the area of past lung infarction. Selective embolization of these vessels through the bronchial artery resulted in the prompt and complete control of the haemoptyses.

\section{References}

1. Malik AB, Tracy SE. Bronchovascular adjustments after pulmonary embolism. J Appl Physiol 1980; 49: 476-481.

2. Parker BM, Smith JR. Studies of experimental pulmonary embolism and infarction and the development of collateral circulation in the affected lung lobe. J Lab Clin Med 1957; 49: 850-857.

3. Orell SR, Hultgren S. Anastamoses between bronchial and pulmonary arteries in pulmonary thromboembolic disease. Acta Path Microbiol Scand 1966; 67: 322-338.

4. Matsuda A. Bronchial arteriography in patients with pulmonary embolism. Chest 1984; 85: 767-773.

5. Endrys J, Hayat N, Cherian G. Comparison of bronchopulmonary collaterals and collateral blood flow in patients with chronic thromboembolic and primary and pulmonary hypertension. Heart 1997; 78: 171-176.

6. Peregrin JH, Kaspar M, Haco M, Vanecek R, Belan A. New occlusive agent for therapeutic embolization tested in dogs. Cardiovasc Intervent Radiol 1984; 7: 97-101. 